\title{
Importance of Ambulatory Blood Pressure Monitoring in Adolescent Hypertension
}

\author{
Denes Palla ${ }^{a}$ Istvan Kiss ${ }^{b} \quad$ Eva Katona $^{a}$ \\ a First Department of Medicine, University of Debrecen, Debrecen, and bepartment of Nephrology-Hypertension, \\ St. Imre Teaching Hospital, and 1st Dialysis Centre of B. Braun Avitum Hungary CPLC, Budapest, Hungary
}

\section{Key Words}

Adolescent hypertension - Ambulatory blood pressure monitoring

\begin{abstract}
There has been a steady increase in the prevalence of adolescent hypertension in recent years. In order to prevent target organ damages, it is important to determine the group of hypertensive adolescents. If repeatedly elevated blood pressure values are observed, with special emphasis on white coat hypertension, which is particularly frequent at this age, ambulatory blood pressure monitoring is highly recommended before pharmacological treatment is started. In addition, performing ambulatory blood pressure monitoring is recommended with target organ damage, resistance to therapy, and suspicion of secondary hypertension. The results of the widely available, simple-to-use device are easy to reproduce.

Copyright $\odot 2011$ S. Karger AG, Basel
\end{abstract}

There has been a steady increase in the prevalence of adolescent hypertension in recent years. Its pathomechanism is not fully known, but, at any rate, in addition to genetic predispositions, environmental and lifestyle factors also seem to play an important role [1], particularly excessive weight. Prevalence has increased from 1 to $4.5 \%$ [2] over the past 10 years. With adolescent hypertension, the simultaneous occurrence of further cardiovascular risk factors is also common [3]. Hypertension is not only a simple disease of elevated blood pressure (BP) but is also a syndrome caused by several cardiovascular risk factors [4].

The significance of hypertension occurring at young ages is provided by the correlations found between adolescent and adult BP readings. This relationship is illustrated by the 'tracking' phenomenon: for individuals whose BP is in a higher percentile during childhood and adolescence, it is likely that they will have their BP in that range during maturation too, therefore it is possible to give a fairly close prediction of who will belong to a highrisk population in adulthood [5]. Since adolescent BP readings are predictive of adult hypertension, early detection of the disease is of great importance. Based on data in the literature we can state that adolescent BP is a risk factor not only for hypertension but also for cardiovascular diseases in adulthood [6].

In adolescence, hypertension is diagnosed if the mean of three consecutive measurements taken on three different occasions exceeds the 95th percentile value of the age-, sex-, and height-specific subgroup's value. Creating the reference values of a particular region greatly increases the chances of a more accurate diagnosis [7].

\section{KARGER \\ Fax +41613061234 E-Mail karger@karger.ch} www.karger.com

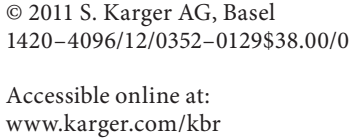

Denes Pall, MD, PhD

First Department of Medicine

Medical and Health Science Center

University of Debrecen, HU-4032 Debrecen (Hungary)

Tel. +36 309657 913, E-Mail pall.denes@ gmail.com 
Diagnosis of hypertension is critically dependent on accurate BP measurement. That is more important in adolescents as the misdiagnosis of hypertension may have a life-long adverse impact on insurability and employment. 24-hour ambulatory blood pressure monitoring (ABPM) offers multiple advantages in achieving high-quality BP determinations by reducing observer errors [8].

\section{Role of ABPM in Light of Guidelines for Adolescents}

ABPM was mentioned in the 1996 guidelines on hypertension in children and adolescents [9]. They show that some data are already known in terms of normal values [10]; however, the guidelines do not find them sufficient to establish reliable reference values. The guidelines also mention that ABPM is becoming increasingly popular in treating adult ABPM, but its wider use in adolescents can only become possible if we have more data at our disposal.

The European guidelines on adolescent hypertension published in 2004 regard casual BP measurements as the gold standard and, although the guidelines consider the use of ABPM necessary in the care of suspected white coat hypertension (WCH), they do not recommend its routine application [3]. The guidelines dedicate a short chapter to ABPM, regarding it, based on literature data, as useful in diagnosing adolescent hypertension $[11,12]$. By frequently measuring $\mathrm{BP}$ and recording the readings, daytime, nighttime and 24-hour ABPM means can also be identified. Using ABPM, we can determine in what percentage of the measurements BP exceeds its normal upper limit ('BP load'). ABPM is particularly favorable in diagnosing $\mathrm{WCH}$ as well as likely target organ damage. The guidelines conclude that in adolescence ABPM should be a tool in the hands of young-age hypertension specialists who are familiar with its use and interpretation of results. However, while recognizing the value of $\mathrm{ABPM}$, the guidelines assign only a limited role to it [13].

In contrast with the shortcomings of casual BP measurements, home BP measurements and 24-hour ABPM offer several advantages and hence they are increasingly being used both as a diagnostic and a therapeutic tool in adulthood [13]. The last decade has seen a welcome increase in the amount of adolescent ABPM. In view of the proliferation of new knowledge, the wide availability and relative ease of the reproducibility of the method, the possibility of its wider application emerges in the diagnosis and therapy of hypertension in young adults.
According to the 2009 guidelines for adolescents of the European Society of Hypertension [14], ABPM is becoming increasingly essential for the diagnosis and therapy of adolescent hypertension [14]. In addition to nocturnal BP variation and $\mathrm{WCH}$, masked hypertension $(\mathrm{MH})$ can only be diagnosed by way of additional use of 24-hour ABPM. In order to adequately assess ABPM, it is necessary to determine clear reference values. In clinical studies involving adolescents, given the lower prevalence of hypertension, the application of ABPM is particularly important [15].

\section{Normal ABPM Values in Adolescence}

BP monitors are validated and calibrated according to the guidelines of the American Association for the Advancement of Medical Instrumentation (AAMI) and the British Hypertension Society (BHS). Of the 43 devices examined, only 9 met the criteria set by the two societies [16], about which up-to-date information can be accessed at www.dableducational.com.

The first study involving a large population of children and adolescents was published by Portman et al. [17] in 1991. This was followed by a publication by Reusz et al. [10] in 1994, in which, in addition to the ABPM readings of 125 healthy schoolchildren, those of young hypertensives and patients known to have kidney disease were also reported on. It was stressed even then that ABPM cannot only be used for diagnostic purposes but that changes in the diurnal rhythm might also suggest changed vasoreactivity. Later on, American, German and Spanish working groups reported on ABPM results [18]. In 1997, Soergel et al. [19] determined reference values based on the ABPM measurements of a total of 1,141 children and adolescents. The study represented a more modern approach since at the time young people's height was also considered in determining normal and pathological values, along with sex and age. Young individuals whose average BP exceeded the 95th percentile of an age-, genderand height-matched group were diagnosed as hypertensive. 2009 saw the publication by the European Society of Hypertension of its guidelines on adolescent hypertension, with German authors' results as reference data (table 1) [20].

The biggest debate concerning the interpretation of results is about determining where the borderline between the normal and the pathological lies, and what aspects this rather arbitrary boundary should be based on. In terms of ABPM, several working groups disagreed with 
Table 1. Systolic and diastolic ABPM values of boys and girls for clinical use based on an article by Wühl et al. [20]

\begin{tabular}{llllllll}
\hline \multirow{2}{*}{$\begin{array}{l}\text { Height } \\
\mathrm{cm}\end{array}$} & \multicolumn{2}{l}{ Daytime } & \multicolumn{5}{l}{ Nighttime } \\
\cline { 2 - 5 } \cline { 6 - 8 } & 75 th & 90 th & 95 th & & 75 th & 90 th & 95 th \\
\hline Boys & & & & & & \\
150 & $120 / 76$ & $125 / 79$ & $128 / 81$ & & $106 / 60$ & $112 / 64$ & $116 / 66$ \\
160 & $124 / 76$ & $129 / 79$ & $133 / 81$ & & $108 / 60$ & $114 / 64$ & $118 / 66$ \\
170 & $128 / 77$ & $134 / 80$ & $138 / 82$ & & $112 / 61$ & $117 / 64$ & $121 / 66$ \\
180 & $132 / 77$ & $138 / 81$ & $142 / 83$ & & $115 / 61$ & $120 / 64$ & $124 / 66$ \\
\hline Girls & & & & & & & \\
145 & $118 / 76$ & $123 / 80$ & $125 / 82$ & & $103 / 59$ & $109 / 63$ & $112 / 66$ \\
155 & $121 / 76$ & $125 / 80$ & $128 / 82$ & & $106 / 59$ & 111663 & $114 / 66$ \\
165 & $123 / 77$ & $127 / 80$ & $130 / 82$ & & $107 / 59$ & $112 / 63$ & $114 / 66$ \\
175 & $125 / 78$ & $129 / 81$ & $131 / 82$ & & $109 / 59$ & $113 / 63$ & $115 / 66$ \\
\hline
\end{tabular}

using the age-, sex-, and height-related 95th percentile values as a limit for hypertension since their BP data suggested a non-gaussian, non-symmetric distribution [20]. They recommended using the LMS method, which could greatly enhance the correct shape of the curve. In calculating the subgroups' data, distribution median (M), the coefficient of variation (S), and the degree of skewness (L) were also considered, greatly decreasing the likelihood of over- and underdiagnosis of hypertension. In adolescence, an accurate diagnosis of hypertension is even more important than in adults as the presence and degree of target organ damage is closely correlated with the time of the persistence of hypertension.

With ABPM, a strict, arbitrary limit in and of itself is not suitable for distinguishing the normal from the pathological. BP load shows what percentage of the measurements is greater than the boundary BP between normal and pathological values. The importance of the issue is further enhanced by the fact that correlations have been found between the above parameter and target organ damage [21]. Three studies have investigated the role of BP load in adolescence. German authors regard values greater than $25 \%$ [22], while others consider values greater than $30 \%$, as abnormal [23]. The authors of the most recent study have determined, based on investigations carried out with 728 youths under age 19, that adolescent $A B P M$ readings are identified as abnormal if, on the one hand, they exceed the 95th percentile BP for the given subgroup, and on the other hand, BP load has reached $30 \%$ [24]. In line with this, the BP of young people is identified as normal if daytime mean is below the 95th percentile, with a BP load lower than 25\% [12].

Importance of ABPM in Adolescent Hypertension
It is necessary for a general consensus to be formed as soon as possible on an evidence-based definition of normal and pathological values for hypertension. In an American study in which three nephrologists interpreted adolescents' ABPM readings independently of each other, only in $64 \%$ of the cases was there complete concordance between the specialists in the question of the diagnosis of hypertension [25]. It is equally necessary to determine the role and weight of the various derived parameters: BP load, BP index (i.e. actual BP divided by the 95th percentile data of the guideline) [26], BP variability [27], lack of nocturnal BP fall ('non-dippers') [28], since there is an increasing amount of evidence to suggest that these parameters are reliable predictors for target organ damage.

\section{Concepts That Can Be Determined Using ABPM}

In the following, we will describe the concepts that can be determined using ABPM, on which there is relative consensus in the literature.

\section{Diurnal Changes of BP}

As with adults, BP of adolescents shows diurnal changes; under normal circumstances the mean of nocturnal readings is at least $10 \%$ lower than that of daytime readings ('dipper'). If the decrease of nighttime BP is lower than this, the 'non-dipper' phenomenon is present. Casual measurements performed in a clinic, at school or at home are not representative of the $24 \mathrm{~h}$ of the day. Multiple readings of ABPM are better suited to diagnose $\mathrm{WCH}$, to investigate the diurnal changes of $\mathrm{BP}$, to follow up on early morning BP surge, to document unexpected drops or elevations in BP, to assess the efficacy of antihypertensive treatment and to follow up on changes in physical activity. The casual measurements of office visits do not necessarily reflect the extra load exerted on target organs.

BP has two phases of maximum value: it is highest in the morning, while a smaller peak can be observed in the afternoon. Nocturnal fall in BP is usually $15-25 \%$, with the lowest value occurring between midnight and 4 a.m. Diurnal changes of systolic BP is sustained in $83 \%$ of young people, the corresponding value for diastolic BP being $89 \%$ [29].

\section{White Coat Hypertension}

$\mathrm{WCH}$ is suspected if measurements taken in an office or clinic show elevated BP values, while those taken in the patient's home are persistently normal. ABPM offers an 
Table 2. Main indications for ABPM in adolescence based on an article by Lurbe et al. [14]

During the process of diagnosis

(a) To confirm hypertension before starting drug treatment

(b) Type 1 diabetes

(c) Chronic kidney disease

During antihypertensive drug treatment

(a) Evaluation of refractory hypertension

(b) Assessment of BP control in adolescence with organ damage

(c) Symptoms of hypotension

Clinical trials normal values while home BP readings as well as ABPM show elevated values. This is the MH phenomenon (or reverse WCH) [38]. Its prevalence in adults coincides with that of WCH. In adolescence, its definition and prevalence are similar to those observed in adults; in the Japanese study mentioned above, prevalence was $11 \%$ [33], and was found to be more common in boys than in girls (19 vs. $5 \%$ ). Lurbe et al. [39] have observed $\mathrm{MH}$ in $7.6 \%$ of adolescents, accompanied by signs of target organ damage, including an increased left ventricular mass index (LVMI).

\section{When Should ABPM Be Applied in Adolescence?}

ABPM is gaining ground in adults, its advantages and indications having found their way into guidelines too. There is evidence that the data provided by ABPM correlates much better with the prevalence of cardiovascular events than that provided by casual measurements [40].

ABPM also offers numerous advantages over casual measurements in adolescents, as the measurements take place during everyday activities on the one hand and nighttime sleep on the other, thus providing continuous data about BP [41]. The reproducibility of ABPM data in adolescents is better than that of office results [42]. ABPM is better correlated with target organ damage than are office measurements [25]. Considering the 'tracking' phenomenon in which adolescent hypertension translates into adult hypertension, it is of great importance that patients with the highest risks should be screened out based on reliable data. The conditions that according to our present knowledge require the performance of ABPM are given a detailed description in table 2, a simplified version of the European Guideline [14].

\section{Special Applications of ABPM}

There is a growing body of data that demonstrates the advantages of ABPM in special populations of young people, particularly kidney patients. In chronic renal failure, ABPM data are better correlated with the glomerular filtration rate than with the data from casual measurements [43]. Lande and Flynn [44] find the accurate determination of young kidney patients' BP so important as to recommend ABPM to prove normotension (i.e. to exclude hypertension) in chronic kidney disease. After renal transplantation, ABPM has proved to be more efficient than casual measurements [45] as renal transplantation 
is characterized by higher nocturnal $\mathrm{BP}$ values, a reversal of the diurnal rhythm [46]. Lack of nocturnal fall in BP and higher nocturnal BP values suggest target organ damage in primary hypertension [47]. A recent publication has shown that normal circadian rhythm is also compromised in obese adolescents, as there is no fall in nighttime BP. A significant number of 'non-dipper' young people are hypertensive, reducing their stamina, with a prevalence of $\mathrm{MH}$ among them at 32.3\% [48].

ABPM data of hypertensive and prehypertensive adolescents were associated with pathologically elevated LVMIs, and the prevalence of left ventricular hypertrophy was also significantly higher [49]. A recent study confirmed that LVMI is higher in sustained hypertensive adolescents than in normotensives, but the white coat hypertensives' LVMI did not differ from them [37].

In addition, ABPM is a good tool for obtaining important data in differentiating between primary and secondary hypertension. If both daytime diastolic and nighttime systolic BP are elevated in adolescence, we have to suspect a diagnosis of secondary hypertension [50]. Further investigation of this phenomenon is especially important when the BP load of daytime diastolic values is greater than $25 \%$ and nighttime systolic BP values exceed $50 \%$. In contrast, if we observe only isolated elevated systolic BP during the day, diagnosis of primary hypertension is likely.

Recent studies of healthy adolescents have shown that if either parent is hypertensive, their own ABPM data are also higher both in terms of daytime and nighttime systolic and diastolic BPs [51]. Parental BP is a strong predictor of their children's BP in the future. A lack of difference between the two groups in casual measurements suggests that ABPM can be used to detect initial differences [52].

\section{Conclusion}

Recent years have seen a proliferation of data on ambulatory adolescent BP monitoring. There is evidence to suggest that its results are better correlated with target organ damage than are casual readings. 24-hour monitoring has proved normotension in $21-47 \%$ of young people diagnosed as being hypertensive based on repeated measurements, which means that $\mathrm{WCH}$ can be diagnosed. This method can also be useful in detecting $\mathrm{MH}$ whose prevalence is $7-11 \%$. It also allows us to gain useful data when secondary hypertension is suspected. Taking the new European consensus guidelines into consideration, it is advisable to take full advantage of the possibilities offered by ABPM, as it is important to confirm diagnoses based on casual measurements. It is imperative to perform ABPM when $\mathrm{WCH}$ or $\mathrm{MH}$ are suspected, to prove target organ damage, and in cases of therapy-resistant hypertension. In adolescence, performing ABPM is considered by the authors to be absolutely necessary before starting antihypertensive medication.

\section{References}

1 Hamet P, Pausova Z, Adarichev V, Adaricheva $\mathrm{K}$, Tremblay J: Hypertension: genes and environment. J Hypertens 1998;16:397-418.

$\checkmark 2$ Sorof JM, Lai D, Turner J Poffenbarger T, Portman RJ: Overweight, ethnicity, and the prevalence of hypertension in school-aged children. Pediatrics 2004;113:475-482.

$\checkmark 3$ National High Blood Pressure Education Program Working Group on High Blood Pressure in Children and Adolescents: The fourth report on the diagnosis, evaluation, and treatment of high blood pressure in children and adolescents. Pediatrics 2004;114: 555-576.

4 Neutel JM: Beyond the sphygmomanometric numbers: hypertension as a syndrome. Am J Hypertens 2001;14:250S-257S.
5 Sánchez-Bayle M, Muñoz-Fernández MT, González-Requejo A: A longitudinal study of blood pressure in Spanish schoolchildren. Working Group of Cardiovascular Risk Factors in Childhood and Adolescence. Arch Dis Child 1999;81:169-171.

-6 Li S, Chen W, Srinivasan SR, Berenson GS: Childhood blood pressure as a predictor of arterial stiffness in young adults: the Bogalusa Heart Study. Hypertension 2004;43: 541-546.

7 Páll D, Katona E, Fülesdi B, Zrínyi M, Zatik J, Bereczki D, et al: Blood pressure distribution in a Hungarian adolescent population: comparison with normal values in the USA. J Hypertens 2003;21:41-47.

8 Graves JW, Althaf MM: Utility of ambulatory blood pressure monitoring in children and adolescents. Pediatr Nephrol 2006;21: $1640-1652$.
$\$ 9$ Update on the 1987 Task Force Report on High Blood Pressure in Children and Adolescents: a working group report from the National High Blood Pressure Education Program. National High Blood Pressure Education Program Working Group on Hypertension Control in Children and Adolescents. Pediatrics 1996;98:649-658.

10 Reusz G, Hóbor M, Tulassay T, Sallay P, Miltényi M: 24-hour blood pressure monitoring in healthy and hypertensive children. Arch Dis Child 1994;70:90-94.

11 Sorof JM, Portman RJ: Ambulatory blood pressure measurements. Curr Opin Pediatr 2001;13:133-137.

$\checkmark 12$ Lurbe E, Sorof JM, Daniels SR: Clinical and research aspects of ambulatory blood pressure monitoring in children. J Pediatr 2004; 144:7-16. 
13 Mancia G, De Backer G, Dominiczak A, Cifkova R, Fagard R, Germano G, et al: 2007 Guidelines for the Management of Arterial Hypertension: The Task Force for the Management of Arterial Hypertension of the ESH and ESC. J Hypertens 2007;25:1105-1187.

-14 Lurbe E, Cifkova R, Cruickshank JK, Dillon MJ, Ferreira I, Invitti C, et al: European Society of Hypertension. Management of high blood pressure in children and adolescents: recommendations of the European Society of Hypertension. J Hypertens 2009;27:17191742 .

-15 Zanchetti A, Mancia G, Black HR, Oparil S, Waeber B, Schmieder RE, et al: Facts and fallacies of blood pressure control in recent trials: implications in the management of patients with hypertension. J Hypertens 2009; 27:673-679.

16 O'Brien E, Atkins N, Staessen J: State of the market. A review of ambulatory blood pressure monitoring devices. Hypertension 1995;26:835-842.

-17 Portman RJ, Yetman RJ, West MS: Efficacy of 24-hour ambulatory blood pressure monitoring in children. J Pediatr 1991;118:842849.

- 18 Lurbe E, Redon J, Liao Y, Tacons J, Cooper RS, Alvarez V: Ambulatory blood pressure monitoring in normotensive children. J Hypertens 1994; 12:1417-1423.

-19 Soergel M, Kirschstein M, Busch C, Danne T, Gellermann J, Holl R, et al: Oscillometric twenty-four-hour ambulatory blood pressure values in healthy children and adolescents: a multicenter trial including 1,141 subjects. J Pediatr 1997;130:178-184.

-20 Wühl E, Witte K, Soergel M, Mehls O, Schaefer F: German Working Group on Pediatric Hypertension. Distribution of 24-hour ambulatory blood pressure in children: normalized reference values and role of body dimensions. J Hypertens 2002;20:1995-2007.

-21 White WB, Schulman P, McCabe EJ, Dey HM: Average daily blood pressure, not office blood pressure, determines cardiac function in patients with hypertension. JAMA 1989; 261:873-877.

-22 Sorof JM, Portman RJ: White coat hypertension in children with elevated casual blood pressure. J Pediatr 2000;137:493-497.

-23 Khan IA, Gajaria M, Stephens D, Balfe JW: Ambulatory blood pressure monitoring in children: a large center's experience. Pediatr Nephrol 2000;14:802-905.

-24 Koshy S, Macarthur C, Luthra S, Gajaria M, Geary D: Ambulatory blood pressure monitoring: mean blood pressure and blood pressure load. Pediatr Nephrol 2005;20:14841486.

25 Kennedy SE, Mackie FE, Rosenberg AR, et al: Agreement on reporting of ambulatory blood pressure monitoring in children. Pediatr Nephrol 2005;20:1766-1768.
6 Sorof JM, Cardwell G, Franco K, Portmann RJ: Ambulatory blood pressure and left ventricular mass index in hypertensive children. Hypertension 2002;39:903-908.

27 Mancia G, Parati G: The role of blood pressure variability in end-organ damage. J Hypertens Suppl 2003;21:S17-S23.

28 Cuspidi C, Macca G, Sampieri L, Fusi V, Severgnini B, Michev I, et al: Target organ damage and non-dipping pattern defined by two sessions of ambulatory blood pressure monitoring in recently diagnosed essential hypertensive patients. J Hypertens 2001; 19: 1539-1545.

29 Lurbe E, Redon J: Ambulatory blood pressure monitoring in children and adolescents: the future. J Hypertens 2000;18:1351-1354.

30 Hornsby JL, Mongan PF, Taylor AT, Treiber FA: 'White coat hypertension' in children. J Fam Pract 1991;33:617-623.

31 Stabouli S, Kotsis V, Toumandis S Papamichael C, Constantopoulos A, Zakopoulos N: White coat and masked hypertension in children: associated with target organ damage. Pediatr Nephrol 2005;20:1151-1155.

\$2 Matsuoka S, Kawamura K, Honda M, Awazu M: White coat effect and white coat hypertension in pediatric patients. Pediatr Nephrol 2002;17:950-953.

33 Parati G, Mancia G: Assessing the white coat effect: which blood pressure measurement should be considered? J Hypertens 2006;24: 29-31.

34 Morić VB, Delmis J, Sepec PM: Ambulatory blood pressure monitoring in children and adolescents - our results. Acta Med Croatica 2008;62(suppl 1):3-6.

35 Floriańczyk T, Werner B: Usefulness of ambulatory blood pressure monitoring in diagnosis of arterial hypertension in children and adolescents. Kardiol Pol 2008;66:12-17.

-36 Sorof JM, Poffenbarger T, Franco K, Portman R: Evaluation of white coat hypertension in children: importance of definitions of normal ambulatory blood pressure and the severity of hypertension. Am J Hypertens 2001; 14:855-860.

-37 Páll D, Juhász M, Lengyel S, Molnár C, Paragh G, Fülesdi B, et al: Assessment of target-organ damage in adolescent white-coat and sustained hypertensives. J Hypertens 2010;28:2139-2144.

38 Pickering TG, Davidson K, Gerin W, Schwartz JE: Masked hypertension. Hypertension 2002;40:795-796.

39 Lurbe E, Torro I, Alvarez V, Nawrot T, Paya $\mathrm{R}$, Redon J, et al: Prevalence, persistence and clinical significance of masked hypertension in youth. Hypertension 2005;45:493-498.
40 Clement DL, De Buyzere ML, De Bacquer DA, de Leeuw PW, Duprez DA, Fagard RH, et al: Office versus Ambulatory Pressure Study Investigators. Prognostic value of ambulatory blood pressure recordings in patients with treated hypertension. N Engl J Med 2003;348:2407-2415.

41 Kiss I (ed): Guidelines for the treatment of high blood pressure in adulthood and childhood. Official Guideline of the Hungarian Society of Hypertension. Hypertens Nephrol 2009;13(suppl 2):81-168.

42 Stergiou GS, Alamara CV, Salgami EV, Vaindirlis IN, Dacou-Voutetakis C, Mountokalakis TD: Reproducibility of home and ambulatory blood pressure in children and adolescents. Blood Pres Monit 2005; 10:143-147.

43 Mitsnefes MM, Kimball TR, Daniels SR: Office and ambulatory blood pressure elevation in children with chronic renal disease. Pediatr Nephrol 2003;18:145-149.

44 Lande MB, Flynn JT: Treatment of hypertension in children and adolescents. Pediatr Nephrol 2009;24:1939-49.

-45 Morgan H, Khan I, Hashmi A, Hebert D, McCrindle BW, Balfe JW: Ambulatory blood pressure monitoring after renal transplantation in children. Pediatr Nephrol 2001;16: 843-847.

46 Lingens N, Dobos E, Witte K. Busch C, Lemmer B, Klaus G, et al: Twenty-four-hour ambulatory blood pressure profiles in pediatric patients after renal transplantation. Pediatr Nephrol 1997;11:23-26.

47 Giaconi S, Levanti C, Fommei E, Innocenti F, Seghieri G, Palla L, et al: Microalbuminuria and casual and ambulatory blood pressure monitoring in normotensives and in patients with borderline and mild essential hypertension. Am J Hypertens 1989;2:259-261.

48 Török K, Pálfi A, Szelényi Z, Molnár D: Circadian variability of blood pressure in obese children. Nutr Metab Cardiovasc Dis 2008; 18:429-435.

49 Stabouli S, Kotsis V, Rizos Z, Toumanidis S, Karagianni C, Constantopoulos A, et al: Left ventricular mass in normotensive, prehypertensive and hypertensive children and adolescents. Pediatr Nephrol 2009;24:15451551.

50 Flynn JT: Differentiation between primary and secondary hypertension in children using ambulatory blood pressure monitoring. Pediatrics 2002;110:89-93.

-51 Alpay H, Ozdemir N, Wühl E, Topuzoğlu A: Ambulatory blood pressure monitoring in healthy children with parental hypertension. Pediatr Nephrol 2009;24:155-161.

-52 Malbora B, Baskin E, Bayrakci US, Agras PI, Cengiz N, Haberal M: Ambulatory blood pressure monitoring of healthy schoolchildren with a family history of hypertension. Ren Fail 2010;32:535-540. 